\title{
Governing antimicrobial resistance: a narrative review of global governance mechanisms
}

\author{
Arne Ruckert $^{1,9}$ (D) Patrick Fafard ${ }^{2}$ (D) . Suzanne Hindmarch ${ }^{3} \cdot$ Andrew Morris $^{4}$. \\ Corinne Packer $^{1} \cdot$ David Patrick $^{5}$ (D) $\cdot$ Scott Weese $^{6}$ (D) $\cdot$ Kumanan Wilson $^{7}$ (D) \\ Alex Wong ${ }^{8} \cdot$ Ronald Labonté $^{1}$ (D)
}

Published online: 9 September 2020

() Springer Nature Limited 2020

\begin{abstract}
Antimicrobial resistance (AMR), a central health challenge of the twenty first century, poses substantial population health risks, with deaths currently estimated to be around 700,000 per year globally. The international community has signaled its commitment to exploring and implementing effective policy responses to AMR, with a Global Action Plan on AMR approved by the World Health Assembly in 2015. Major governance challenges could thwart collective efforts to address AMR, along with limited knowledge about how to design effective global governance mechanisms. To identify common ground for more coordinated global actions we conducted a narrative review to map dominant ideas and academic debates about AMR governance. We found two categories of global governance mechanisms: binding and non-binding and discuss advantages and drawbacks of each. We suggest that a combination of non-binding and binding governance mechanisms supported by leading antimicrobial use countries and important AMR stakeholders, and informed by One Health principles, may be best suited to tackle AMR.
\end{abstract}

Keywords Antimicrobial resistance $\cdot$ Global governance $\cdot$ International law $\cdot$ Health regulations

\section{Abbreviations}
AMR Antimicrobial resistance
FAO Food and Agricultural Organization
GLASS Global Antimicrobial Surveillance System
IHRs International Health Regulations
IPC Infection Prevention and Control

\footnotetext{
Electronic supplementary material The online version of this article (https://doi.org/10.1057/s4127
} 1-020-00248-9) contains supplementary material, which is available to authorized users.

Arne Ruckert

aruckert@uottawa.ca

Extended author information available on the last page of the article 


$\begin{array}{ll}\text { OIE } & \text { World Organisation for Animal Health } \\ \text { PHEIC } & \text { Public Health Emergency of International Concern } \\ \text { PPP } & \text { Public-private partnership } \\ \text { SDGs } & \text { Sustainable development goals } \\ \text { WHO } & \text { Wold Health Organization } \\ \text { WTO } & \text { World Trade Organization }\end{array}$

\section{Introduction}

Antimicrobial resistance (AMR) has been widely recognized as one of the central health challenges of the twenty first century [1-3]. Since discovery of antibiotics, they have been a cornerstone of modern medicine $[4,5]$. AMR predates human use of antibiotics and is naturally occurring as the outcome of the evolutionary adaptation process of microbes. But it has become increasingly clear that use of antibiotics, both in human and veterinarian practice and agriculture and animal husbandry, contributes to antimicrobial resistance [6]. AMR poses significant population health risks, with annual deaths estimated to be around 700,000 globally [7]. The international community recently identified it as a major threat to achievement of the Sustainable Development Goals, SDGs [8]. AMR has potential to disrupt the global economy as severely as the Global Financial Crisis of 2008/2009, with an eventual cost in the trillions of dollars if unaddressed [2]. The recent COVID-19 outbreak and widespread use of antibiotics with it have raised concerns about the potential of the global pandemic to speed up antimicrobial resistance [9].

The international community signaled its commitment to exploring effective policy responses, with a Global Action Plan on AMR approved by the World Health Assembly in 2015 [10]. Major governance challenges could thwart collective efforts to address AMR. We reflect through a narrative review of binding and non-binding governance mechanisms discussed in the academic literature on AMR. By mapping these debates, we aim to inform decision-making about the global governance of AMR — particularly by identifying potential points of agreement as starting points for strengthening a global AMR response.

In a growing body of literature about AMR governance, many authors begin from a normative preference for a specific governance mechanism, then build a case for that preferred mechanism [4]. We take a 'step back' to map the preferences and debates, then seek the global governance options that appear most feasible. Identifying options for improved global governance of AMR is vitally important; despite declaring firm commitment, many countries have not implemented national action plans or taken even sporadic actions to better align the domestic policies with global recommendations [11]. Various sectors involved in AMR governance have conflicting interests (such as human and animal health, agriculture, the pharmaceutical industry, and the environment) which could impede collaboration and challenge implementation of solutions - such as enhanced AMR surveillance across sectors or addressing excessive use of antimicrobials in agriculture and horticulture [12]. Addressing AMR will require global collaboration because no single country can prevent or mitigate AMR through its own actions [13]. As a global common good, 
safeguarding antimicrobial effectiveness and mitigating the threat of AMR in a collaborative fashion are necessarily a responsibility of all countries and multilateral organizations.

The Global Action Plan produced by the World Health Organization, WHO [10], and similar action plans by the Food and Agricultural Organization, FAO [14] and the World Organization for Animal Health, OIE [15], identify five areas of essential global collective action to address AMR:

- effective antimicrobial surveillance;

- better infection prevention and control (IPC) measures;

- global awareness campaigns;

- promoting responsible use through stewardship;

- innovation for successful containment of AMR emergence and spread, including through development of novel antimicrobial drugs.

Thus, we address the question: Which global governance modalities and mechanisms are most likely to produce an effective AMR response?

\section{Methods}

We conducted a narrative review to identify global governance mechanisms to address AMR currently explored in the academic literature [16]. Because the global AMR response is at a relatively early stage and lacks consensus about how best to proceed, this approach allowed us to map out the dominant topics and debates as a first step toward identifying common ground for a basis of more coordinated global action. We used two electronic databases (Scopus and Pubmed) to identify relevant articles $(n=411)$ and a Boolean search strategy (see Supplementary Materials File). By screening abstracts we identified 43 relevant articles and added 7 more recommended by reviewers during the revision process (for a total of $n=50$ ). After removing duplicates, we retained 38 articles using the following inclusion criteria: (1) identifies governance mechanisms to address AMR; (2) discusses policy framings of AMR; (3) provides policy solutions to effective AMR governance; (4) identifies barriers to, or facilitators of, effective AMR governance; and (5) has been published since 2000. We imported articles into NVivo 10 and conducted a constant comparative analysis based on a deductively developed coding structure, enriched inductively as new ideas and concepts emerged (see Supplemental Materials File). A limitation is that we included only English language articles.

\section{Results}

AMR governance mechanisms fit in two categories: binding or non-binding. Global governance attempts to achieve a purposeful order from institutions, processes, norms, formal agreements, and informal mechanisms that regulate action for a 
common good, with the question of enforcement of global rules are central to most academic discussions of global governance [17].

\section{Binding governance mechanism}

Binding governance mechanisms include treaties, covenants, protocols, and accords - the 'gold standard' in global health governance [4] - because they hold signatories legally responsible and accountable. No such agreement on AMR presently exists. The literature considers two approaches-treaties and regulations, each with advantages and disadvantages. Some global governance scholars propose developing an international treaty to rectify the current fragmented approach and lack of leadership [18-22]. One notes: "A treaty on managing antimicrobials and containing AMR emergence and spread could help coordinate efforts in this area, especially when combined with strong implementation mechanisms and regulatory functions" [4]. A treaty to promote international compliance would also help to minimize market and competitive disadvantages in particular industries. Without such a treaty, a nation's livestock producers who refrained from using antimicrobial growth promoters could be disadvantaged by producers in other countries who did not [19]. A treaty could promote a global system to facilitate coordination and the legalization of gathering and sharing of surveillance data, and improve transparency and accountability [18].

A global treaty, if established per article 19 of the WHO Constitution, could also promote wide-scale reductions of infection rates by improving implementation of Infection Prevention and Control (IPC) through development and enforcement of guidelines on sanitation, mapping of microbial spread patterns, and setting standards for infection prevention and control practices [23]. It could promote stewardship programs, product labelling requirements, better medical waste management policies, and improved sanitation measures by States, for example, by setting desirable benchmarks for antimicrobial use [23]. A treaty could also impose a global marketing ban on antimicrobials as one element of a larger antimicrobial conservation strategy [19].

The review revealed considerable challenges and several arguments against pursuing it. Reconciling diverse stakeholder interests is one hurdle. States are unlikely to support an international agreement unless it would benefit domestic stakeholders, especially if the corporate sector lobbies against new regulations; all actors must find that benefits outweigh costs and potential harm [18]. A treaty would likely include an obligation to report regularly on compliance, and few countries have infrastructure or reporting mechanisms for meaningful reporting (observed in partial reporting under the Global Antimicrobial Resistance Surveillance System [24]).

In addition to Treaties, regulations can also be legally binding under international law. Regulations on antimicrobial use could have binding targets for agricultural use of antibiotics [12, 25]. Thakur and Panda [26] recommend banning use of all medically important antibiotics in food for animals through global harmonization. The goal is to preserve their effectiveness for necessary medical use. This approach might require global harmonization of categorization and terminology, because what 
constitutes 'medically important', 'highly important', 'critically important', or 'highest priority critically important antimicrobials' varies across countries. The variations may create confusion - a barrier to effective regulation. Regulations could also ban over-the-counter sale of antibiotics and online sale of antimicrobials without prescription globally [12]. Regulation can also encompass quality standards. Bloom et al. argue that governments should coordinate their actions globally, set quality standards for drugs and treatment guidelines, and negotiate the contents of advertising material to limit counterfeit and substandard drugs and influence the packaging and marketing of pharmaceutical drugs [27]. They recommend that this process involve the pharmaceutical sector and leaders of the medical profession to encourage adherence to regulations and quality standards.

Wernli et al. suggest that emergence and spread of antimicrobial-resistant bacteria, especially those involving new pan-resistant strains for which there are no suitable treatments, may constitute a public health emergency of international concern (PHEIC). Under these circumstances, countries should be required to notify the World Health Organization under the International Health Regulations, IHRs [25]. The IHRs provide a legal framework for international efforts to contain spread of acute health risks, including a surveillance and a global alert system, definitions of core public health capacities for surveillance and response in all countries, and WHO guidance through standing recommendations. Applying the IHRs to AMR could "serve as a 'wake-up call' and strengthen global AMR surveillance and response, which could in turn contribute to containing the spread of AMR" [25].

Another article highlights that, given the prevalence of drug resistant bacteria in traded food commodities, trade agreements should increasingly consider AMR, especially in discussions and adjudication of disputes over intellectual property protection [28]. Here the Codex Alimentarius Commission and the World Organization for Animal Health (OIE) play important roles because World Trade Organization members and countries party to other bilateral or regional trade agreements must base regulations on international standards. By establishing stronger regulations these bodies could help tackle AMR and contribute to achieving the sustainable development goals [28]. Some raise concerns that existing trade agreements might hamper antimicrobial stewardship initiatives, for example by limiting policy space to restrict food imports from countries that overuse antibiotics [29]. The European Commission raised this issue recently in connection with its ban on antimicrobials to boost growth and yield. Some scholars ask whether this new European Union (EU) legislation could be challenged at the WTO by a country importing food into the EU.

\section{Non-binding governance mechanisms}

The literature discusses non-binding governance mechanisms including political declarations, resolutions, and operational guidelines; public-private partnerships (PPP) based governance mechanisms; and voluntary (consumer and industry driven) governance initiatives. 
Political declarations (resolutions or operational guidelines) cannot compel action, but can foster consensus and cooperation through gradual diffusion of norms [4]. One article notes: "political declarations offer a nimbler, more adaptive option to the rigidity of legally binding global governance mechanisms such as treaties, and [...] allow for more dynamic discourse and better responsiveness to changing global priorities" for AMR [4]. Another highlights that non-binding and participatory governance mechanisms could incorporate incentives to private industry to participate in antimicrobial stewardship and surveillance initiatives [30]. Another approach involves a voluntary Global Antimicrobial Conservation Fund to provide a transnational resource transfer to boost capacities and program development in the lowest income countries:

Such a fund would not diminish the responsibility of national governments in the development of their national AMR plans nor for delivering meaningful outputs. Rather, it would confer support for accelerated action to conserve a rapidly dwindling resource and could be linked to a formal resource conservation agreement [31].

A pooled fund with contributions tied to gross national income could ensure that assistance supports implementation of the AMR Global Action Plan [32]. Not all commentators agree; some warn that normatively based international agreements on AMR would lack effective mechanisms for transparency, oversight, and complaint, providing little international pressure or incentives for countries to comply with the unenforceable terms [19].

The literature also offers financial models to spur the development of new antibiotics, particularly discovery of new drug classes. The use of PPPs has a long history in drug innovation, for example with neglected tropical diseases [33]. Given a recent slow-down in commercial development of antimicrobial drugs, analysts have identified PPPs as a potential solution to some challenges of developing new antimicrobials. These include high initial development costs; the low price point of most antimicrobials; and the need to limit the use of new drugs once they become available to ensure efficacy over time. One article highlights that,

given the economics of the development of new antibiotics, profits from 'drugs of last resort' might not justify investment in this area by private pharmaceutical companies alone. Solutions therefore need to include government action in industrialized countries to overcome this 'market failure' by both reducing regulatory barriers to entry and improving the economic incentives for re-engagement by private enterprises [34].

Global governance mechanisms to foster drug innovation should explore and encourage PPPs, particularly for treatment of infections in economically disadvantaged parts of the world [35].

Following this logic, government, non-governmental and intergovernmental agencies have called for the development of PPPs and innovative funding mechanisms for AMR. In its Global Action Plan, the WHO calls for new partnership 
models "for providing incentives for innovation and promoting cooperation among policy-makers, academia and the pharmaceutical industry to ensure that new technologies are available globally to prevent, diagnose and treat resistant infections" [10]. The Innovative Medicines Initiative Joint Undertaking Programme in Europe is a prominent example for drug innovation that has invested more than $€ 660$ million. It seeks matching contributions from the European Commission and the European Federation of Pharmaceutical Industries and Associations. Through the New Drugs for Bad Bugs Programme, this initiative invests in promising research to fight against AMR "at every level from basic science and drug discovery, through clinical development to new business models and responsible use of antibiotics" [36]. Another global partnership, Carb-X, accelerates antibacterial research to tackle the global rising threat of drug-resistant bacteria. It boasts the world's largest early development pipeline of new antibiotics, vaccines, rapid diagnostics, and other products to prevent and treat life-threatening bacterial infections.

Some articles focus on the potential roles for non-state actors, voluntary industry initiatives, and other forms of self-regulation in AMR governance [30]. Canada established a deadline of 2014 for voluntary phasing out of Category I antibiotics, those most important to human health, for the chicken industry. In May 2017, the Chicken Farmers of Canada announced a plan to eliminate preventative use of Category II antibiotics by the end of 2018 and a goal to eliminate preventive use of Category III antibiotics by the end of 2020 [37]. Growing popular awareness of the risks of the presence of antimicrobials in the food chain and related changes in consumer choices drive these initiatives.

\section{Discussion}

The range of binding and non-binding mechanisms proposed indicates a lack of consensus about how best to proceed. It also affirms the complexity of AMR as a policy problem. What are the strengths and weaknesses of each approach? And, what are shared principles to undergird an effective governance regime to address AMR?

Currently AMR global governance relies entirely on non-binding governance mechanisms. The World Health Assembly Resolution 68/20, the associated Global Action Plan on AMR [10], and the UN General Assembly's Political Declaration on AMR (Resolution 71/3) [38] are the strongest of nonbinding global governance mechanisms implemented. Their champions hope these will encourage decisive and lasting global action to curb AMR. In theory, such mechanisms could facilitate country driven actions and policy ownership_and increase likelihood that countries implement national-level actions. Although voluntary in nature, nonbinding mechanisms may use stronger implementation language than legally binding treaties, and integrate civil society organizations and non-state actors into implementation. This provides political and legal support without the legal consequences of binding governance mechanisms if states fail to meet their commitments [4]. Voluntary contributions and a bottom-up approach to AMR would allow low- and middle-income countries to balance safeguarding of antimicrobials with other priorities, 
such as economic development and food security-and could increase political support among these states. Despite the benefits that hierarchical governance might offer through an enforceable treaty, a non-binding network approach could increase shared responsibility to reach goals and more sustainable governance of AMR [30].

Failure by many countries to voluntarily adhere to the commitments inscribed in the Global Action Plan, however, is a major concern. The 2017/2018 WHO report on AMR implementation shows that 43 countries developed, or implement national AMR action plans reflecting objectives of the Global Action Plan; only 19 countries have directly allocated funding to implement action plans, engaged relevant sectors, and designed a monitoring and evaluation process (as recommended by WHO) [11]. Aguirre finds that despite needed concerted global effort, only $25 \%$ of countries have implemented a national policy to address antibiotic resistance [39]. It is not surprising that low-income countries might find it difficult to identify resources to develop and implement an intersectoral AMR action plan. But middle- and high-income countries are falling behind as well: only 23 European countries had approved an adequate action plan by 2017 [11]. Voluntary governance mechanisms related to climate change and the Sustainable Development Goals (SDGs) have also shown limited impact on state behavior; countries are already falling behind with their voluntary 'nationally determined contributions' (NDCs) to mitigate climate change (agreed upon at the COP 21 Paris Climate Summit) [40].

Concerns that voluntary reporting mechanisms might lack transparency and consistency arise; thus assessing progress might prove difficult. Previous experiences of reliance on voluntary governance mechanisms without enforcement instruments indicate limits of norm change as a means to catalyze effective and efficient state action. Binding governance mechanisms may be needed. The ad hoc Inter-Agency Coordination Group (IACG) for the Governance of Antimicrobial Resistance (made up of WHO, FAO, OIE, and various individual experts), acknowledged this recently in laying out a vision for achieving a global treaty within 10 years, either an intergovernmental treaty or a multi-stakeholder AMR Protocol [41].

The limits of non-binding governance mechanisms may lend support to the literature advocating a legally binding AMR treaty to ensure national compliance with governance principles established at the global level. One recent precedent, the Framework Convention on Tobacco Control (FCTC), may offer lessons about the impact of international treaties on health governance. A recent review argues:

The influence of the WHO FCTC in global governance can be at least partially attributed to its status as an international legal obligation. While tobacco control would have likely been a priority in international public health even in the absence of the WHO FCTC, the importance of tobacco control has been relatively greater as a result of the treaty [42].

AMR, however, poses a very different set of public health problems from tobacco control: it is transboundary, multisectoral, and constantly evolving in a way that tobacco control is not. Given these differences, to what extent can lessons from the FCTC can be applied to AMR governance? Also, binding agreements face their own challenges. For example, only 37 industrialized countries committed to legally binding reductions in emissions in the Kyoto Protocol, one of the most prominent 
binding global governance efforts. Even the committed countries have mixed compliance results [43]. A binding global agreement is no guarantee of effective domestic actions, especially without political mobilization [44]. Yet, even when expected benefits from binding legal agreements are marginal, such agreements may be useful in supporting implementation of domestic AMR policies-albeit incrementally and indirectly:

- They might contribute to norm change, and therefore incentivize governments to participate in AMR-related activities [18].

- They could assist domestic non-governmental AMR actors in advocating for policy change.

Lack of consensus, scholarly or political, about how best to structure AMR governance indicates major barriers to achieving a binding agreement soon:

- To be politically feasible, states and stakeholders must perceive the benefits of any AMR treaty or agreement to outweigh current and projected costs and potential health and economic harms [24]. At a minimum, this would require concerted education campaigns amongst stakeholders, and incentive schemes for industry to partake in stewardship. Even then, a widespread perception that a treaty is unlikely if not supported by the most powerful economic countries, especially the United States, China, and Japan, could hinder progress. Creation of a 'coalition of the willing' might mitigate resistance and entice others to join global AMR efforts [24]. Ideally a coalition would include 'initiator countries' (those leading reduction of antibiotic use) and 'pivotal countries', (those with strong influence due to economic and political power).

- Particularly low-income countries may perceive treaties that impose domestic obligations as coercive and paternalistic; standard setting in international treaties are largely dictated by high-income countries on the basis of policy guidelines/ actions that these countries already meet. Ensuring development of governance rules in international fora or by international organizations in which countries have equal standing (the WHO versus World Bank), and ensuring any international treaty includes binding agreements for resource transfer from North-South (HIC-LIC) might mitigate this barrier.

Our review did find virtually unanimous agreement on a key principle to undergird effective global governance: all efforts, legally binding or nonbinding, should approach AMR through a One Health lens to address human, animal, and environmental health and their complex interactions [4]. One Health entails balancing of competing interests across sectors, while privileging human over animal health: "Typically, human health interests should predominate, but animal health and welfare are also important considerations,... economic interests are subordinate to health considerations" and "antimicrobial stewardship programs should seek to ensure that antimicrobials are reserved for the treatment of clinical infections in humans" [45]. Apparent consensus about One Health may indicate the emergence of a new norm as a promising foundation for coordination. Over 
time, it could generate the shared political will required to support development of more robust binding mechanisms.

\section{Conclusion}

Our review indicates strong interest in and a good rationale for top-down global governance mechanisms to address AMR. A lack of consensus persists, however, about which specific mechanisms are most desirable, politically feasible, and likely to be effective. Deep and divergent perspectives remain (often implicit rather than explicitly stated) about the causal relation between legal and normative change:

- Is norm change a necessary antecedent to generating the political will required to produce legal change in the form of a binding agreement?

- Or does legal change, by compelling changes in actors' behavior and policies, represent the catalyst for a subsequent change in reinforcing norms?

Clearly, securing an international treaty and enforceable market regulations might not be sufficient to address AMR, especially if the biggest user countries of antimicrobials, and the agricultural industries in them, remain opposed to strong AMR regulations. Currently, this seems to be the case. A reduction of AMR consumption might therefore best be achieved by combining a governance system with an enforceable treaty (initially with those countries willing to volunteer), with the development of various non-binding governance and stewardship initiatives with engagement of important stakeholders to raise awareness and shift deeply entrenched human and animal health practices. Thus, we advocate combining pressure from below (by civil society and progressive actors promoting grass-roots solutions to AMR) with pressure from above (through international legal obligations) that could generate momentum towards implementation of effective policy solutions to this important global health issue.

Author contributions All authors contributed to the study design. Data collection and coding of data was led by AR and RL. All authors equally contributed to drafting the manuscript and approved the final version of the article.

Funding The study received funding from the Canadian Institute of Health Research through Operating Grant No. 156843. The study received logistical support from the One Health Network on the Global Governance of Infectious Disease and Antimicrobial Resistance (Global 1HN).

\section{Compliance with ethical standards}

Conflict of interest The authors have no competing interests to declare.

Ethical approval The study received ethics approval from the University of Ottawa Ethics Review Board. 


\section{References}

1. Organization for Economic Development and Cooperation. Antimicrobial resistance in G7 countries and beyond: policy brief. Organization for Economic Development and Cooperation; 2015 (cited 25 Sep 2017). https://www.oecd.org/els/health-systems/Antimicrobial-Resistance-inG7-Countries-and-Beyond-Policy-Brief.pdf.

2. World Bank. Drug-resistant infections; a threat to our economic future. Washington, DC: World Bank Group; 2017 (cited 1 Aug 2018). https://documents.worldbank.org/curated/en/3233114933 96993758/pdf/114679-REVISED-v2-Drug-Resistant-Infections-Final-Report.pdf.

3. World Health Organization. Tackling antimicrobial resistance: ensuring-sustainable R\&D. World Health Organization; 2017 (cited 25 Sep 2017). https://www.oecd.org/g20/summits/hamburg/ Tackling-Antimicrobial-Resistance-Ensuring-Sustainable-RD.pdf.

4. Padiyara $P$, Inoue $H$, Sprenger $M$. Global governance mechanisms to address antimicrobial resistance. Infect Dis. 2018;11 (cited 6 Dec 2018). https:/www.ncbi.nlm.nih.gov/pmc/articles/ PMC5900814/.

5. Paphitou NI. Antimicrobial resistance: action to combat the rising microbial challenges. Int $\mathbf{J}$ Antimicrob Agents. 2013;42(Supp1):S25-S2828.

6. Martin MJ, Thottathil SE, Newman TB. Antibiotics overuse in animal agriculture: a call to action for health care providers. Am J Public Health. 2015;105(12):2409-10.

7. O’Neill J. Tackling drug-resistant infections globally: final report and recommendations. London: United Kingdom Review on Antimicrobial Resistance; 2016 (cited 1 Aug 2018). https:// amr-review.org/sites/default/files/160525_Final\%2520paper_with\%2520cover.pdf.

8. Jasovský D, Littmann J, Zorzet A, Cars O. Antimicrobial resistance-a threat to the world's sustainable development. Ups J Med Sci. 2016;121(3):159-64.

9. Antimicrobial resistance in the age of COVID-19. Nat Microbiol. 2020;5:779. https://doi. org/10.1038/s41564-020-0739-4.

10. World Health Organization. Global Action Plan: Antimicrobial Resistance. Geneva: WHO; 2015 (cited 7 Aug 2018). https://www.wpro.who.int/entity/drug_resistance/resources/global_action_ plan_eng.pdf.

11. FAO, OIE, WHO. Monitoring global progress on addressing antimicrobial resistance. Geneva: WHO; 2018. p. 1-68 (cited 1 Aug 2018). https://apps.who.int/iris/bitstream/handle/10665/27312 8/9789241514422-eng.pdf?ua=1.

12. Metcalfe S, Baker MG, Freeman J, Wilson N, Murray P. Combating antimicrobial resistance demands nation-wide action and global governance. N Z Med J. 2016;129(1444):8-14.

13. Rochford C, Sridhar D, Woods N, Saleh Z, Hartenstein L, Ahlawat H, et al. Global governance of antimicrobial resistance. Lancet. 2018;391(10134):1976-8.

14. FAO. The FAO Action Plan on Antimicrobial Resistance 2016-2020. Rome: Food and Agriculture Organization; 2016, p 25.

15. OIE. The OIE strategy on antimicrobial resistance and the prudent use of antimicrobials. Paris: World Organisation for Animal Health; 2016 (cited 1 Aug 2018). https://www.oie.int/fileadmin/ Home/eng/Media_Center/docs/pdf/PortailAMR/EN_OIE-AMRstrategy.pdf.

16. Arksey H, O’Malley L. Scoping studies: towards a methodological framework. Int J Soc Res Methodol. 2005;8(1):19-32.

17. Benedict K. Global governance. In: Smelser NJ, Baltes PB, editors. International encyclopedia of the social and behavioral sciences. Oxford: Pergamon; 2001. p. 6232-7 (cited 26 June 2020). https://www.sciencedirect.com/science/article/pii/B0080430767044995.

18. Hoffman SJ, Behdinan A. Towards an international treaty on antimicrobial resistance. Ott Rev. 2016;47:507.

19. Hoffman SJ, Ottersen T. Addressing antibiotic resistance requires robust international accountability mechanisms. J Law Med Ethics. 2015;43(S3):53-64.

20. Hoffman SJ, Outterson K, Røttingen J-A, Cars O, Clift C, Rizvi Z, et al. An international legal framework to address antimicrobial resistance. Bull World Health Organ. 2015;93(2):66.

21. Hoffman SJ, Røttingen J-A, Frenk J. Assessing proposals for new global health treaties: an analytic framework. Am J Public Health. 2015;105(8):1523-30.

22. Rizvi Z, Hoffman SJ. Effective global action on antibiotic resistance requires careful consideration of convening forums. J Law Med Ethics. 2015;43(Suppl 3):74-8. 
23. Gulati N, Nyonator JP, Pinto K-J, Roy É, Sauvé C. In: Hoffman SJ, Sritharan L, editors. Global Health Law Clinic: using international instruments to address antimicrobial resistance. Global Health Law Clinic publication series. Ottawa: University of Ottawa; 2016, p. 1-32 (cited 7 Jan 2019). https://globalstrategylab.org/files/globalstrategylab/files/global_health_law_clinic_who_ report_new_website.pdf.

24. Van Katwyk SR, Danik MÉ, Pantis I, Smith R, Røttingen J-A, Hoffman SJ. Developing an approach to assessing the political feasibility of global collective action and an international agreement on antimicrobial resistance. Glob Health Res Policy. 2016;1(1):20.

25. Wernli D, Haustein T, Conly J, Carmeli Y, Kickbusch I, Harbarth S. A call for action: the application of the international health regulations to the global threat of antimicrobial resistance. PLoS Med. 2011;8(4) (cited 26 March 2019). https://www.ncbi.nlm.nih.gov/pmc/articles/PMC3079636/.

26. Thakur SD, Panda AK. Rational use of antimicrobials in animal production: a prerequisite to stem the tide of antimicrobial resistance. Curr Sci. 2017;113(10):1846-57.

27. Bloom G, Merrett GB, Wilkinson A, Lin V, Paulin S. Antimicrobial resistance and universal health coverage. BMJ Glob Health. 2017;2(4):e000518.

28. Hanefeld J, Khan M, Tomson G, Smith R. Trade is central to achieving the sustainable development goals: a case study of antimicrobial resistance. BMJ. 2017;358:j3505.

29. George A. Antimicrobial resistance, trade, food safety and security. One Health. 2018;5(June):6-8.

30. Birgand G, Castro-Sánchez E, Hansen S, Gastmeier P, Lucet J-C, Ferlie E, et al. Comparison of governance approaches for the control of antimicrobial resistance: analysis of three European countries. Antimicrob Resist Infect Control. 2018;7 (cited 17 April 2018). https://www.ncbi.nlm.nih.gov/pmc/ articles/PMC5819189/.

31. Mendelson M, Dar OA, Hoffman SJ, Laxminarayan R, Mpundu MM, Røttingen J-A. A Global Antimicrobial Conservation Fund for low- and middle-income countries. Int $\mathrm{J}$ Infect Dis. 2016;51(1):70-2.

32. Andresen S, Hoffman SJ. Much can be learned about addressing antibiotic resistance from multilateral environmental agreements. J Law Med Ethics. 2015;43(S3):46-52.

33. Nwaka S, Ridley RG. Virtual drug discovery and development for neglected diseases through public-private partnerships. Nat Rev Drug Discov. 2003;2(11):919-28.

34. Bush K, Courvalin P, Dantas G, Davies J, Eisenstein B, Huovinen P, et al. Tackling antibiotic resistance. Nat Rev Microbiol. 2011;9(12):894-6.

35. de Vrueh RLA, Crommelin DJA. Reflections on the future of pharmaceutical public-private partnerships: from input to impact. Pharm Res. 2017;34(10):1985-99.

36. Kostyanev T, Bonten MJM, O’Brien S, Steel H, Ross S, François B, et al. The Innovative Medicines Initiative's New Drugs for Bad Bugs Programme: European public-private partnerships for the development of new strategies to tackle antibiotic resistance. J Antimicrob Chemother. 2016;71(2):290-5.

37. Chicken Farmers of Canada. What matters to us: antibiotics. Chicken Farmers of Canada; 2017 (cited 13 July 2015). https://www.chickenfarmers.ca/what-matters-to-us/antibiotics/.

38. United Nations General Assembly. Political Declaration of the High-Level Meeting of the General Assembly on Antimicrobial Resistance. United Nations General Assembly; 2016 (cited 12 Dec 2018). https://digitallibrary.un.org/record/842813/files/A_71_L-2-EN.pdf.

39. Aguirre E. An international model for antibiotics regulation. Food Drug Law J. 2017;72(2):295-313.

40. Pauw WP, Klein RJT, Mbeva K, Dzebo A, Cassanmagnago D, Rudloff A. Beyond headline mitigation numbers: we need more transparent and comparable NDCs to achieve the Paris Agreement on Climate Change. Clim Change. 2018;147(1):23-9.

41. Interagency Coordination Group on Antimicrobial Resistance. Future global governance for Antimicrobial Resistance. Interagency Coordination Group on Antimicrobial Resistance; 2018 (cited 12 Dec 2018). https://www.who.int/antimicrobial-resistance/interagency-coordination-group/IACG_ Future_global_governance_for_AMR_120718.pdf.

42. McInerney TF. WHO FCTC and global governance: effects and implications for future global public health instruments. Tob Control. 2018. https://doi.org/10.1136/tobaccocontrol-2018-054358

43. Rubin O. The glocalization of antimicrobial stewardship. Glob Health. 2019;15(1):54.

44. Van Katwyk SR, Giubilini A, Kirchhelle C, Weldon I, Harrison M, McLean A, et al. Exploring models for an international legal agreement on the global antimicrobial commons: lessons from climate agreements. Health Care Anal. 2020. https://doi.org/10.1007/s10728-019-00389-3

45. McEwen SA, Collignon PJ. Antimicrobial resistance: a One Health perspective. Microbiol Spectr. 2018;6(2). https://www.asmscience.org/docserver/fulltext/microbiolspec/6/2/ARBA-0009-2017. 
pdf? expires $=1546887637 \&$ id $=\mathrm{id} \&$ acc name $=$ esid053691 \& checksum $=8509$ C8696B5E0A369BD7 7305BC4E6FE8.

Publisher's Note Springer Nature remains neutral with regard to jurisdictional claims in published maps and institutional affiliations.

Arne Ruckert PhD, is Senior Research Associate at the University of Ottawa, School of Epidemiology and Public Health, Ottawa, Ontario, Canada.

Patrick Fafard $\mathrm{PhD}$, is Professor at the University of Ottawa, Graduate School of Public and International Affairs, Ottawa, Ontario, Canada.

Suzanne Hindmarch $\mathrm{PhD}$, is Associate Professor at the University of New Brunswick, Department of Political Science, Fredericton, New Brunswick, Canada.

Andrew Morris MD, MSc, is Professor at the University of Toronto, Faculty of Medicine, Toronto, Ontario, Canada.

Corinne Packer $\mathrm{PhD}$, is Senior Research Associate at the University of Ottawa, School of Epidemiology and Public Health, Ottawa, Ontario, Canada.

David Patrick MD, MHSc, is Professor at the University of British Columbia, School of Population and Public Health, Vancouver, British Columbia, Canada.

Scott Weese DVM, DVSc, is Professor at the University of Guelph, Department of Pathobiology, Ontario Veterinary College, Guelph, Ontario, Canada.

Kumanan Wilson MD, MSc, is Professor at the Ottawa Hospital, Civic Campus, Ottawa, Ontario, Canada.

Alex Wong $\mathrm{PhD}$, is Associate Professor at Carleton University, Department of Biology, Ottawa, Ontario, Canada.

Ronald Labonté $\mathrm{PhD}$, is Distinguished Research Chair and Professor at the University of Ottawa, School of Epidemiology and Public Health, Ottawa, Ontario, Canada.

\section{Affiliations}

\section{Arne Ruckert ${ }^{1,9}$ (D) Patrick Fafard ${ }^{2}$ D $\cdot$ Suzanne Hindmarch ${ }^{3} \cdot$ Andrew Morris $^{4}$. Corinne Packer ${ }^{1} \cdot$ David Patrick $^{5}$ (D) Scott Weese ${ }^{6}$ (D) Kumanan Wilson ${ }^{7}$ (D) Alex Wong ${ }^{8} \cdot$ Ronald Labonté $^{1}$ D}

1 Corinne School of Epidemiology and Public Health, University of Ottawa, 600 Peter Morand Crescent, Ottawa, ON K1G 3Z7, Canada

2 Graduate School of Public and International Affairs, University of Ottawa, 120 University Private, Ottawa, ON K1N 6N5, Canada

3 Department of Political Science, University of New Brunswick, 3 Bailey Drive, Fredericton, NB E3B 5A3, Canada

4 Faculty of Medicine, University of Toronto, Medical Sciences Building, 1 King's College Cir, Toronto, ON M5S 1A8, Canada

5 School of Population and Public Health, University of British Columbia, East Mall, Vancouver, 
BC V6T 1Z3, Canada

6 Department of Pathobiology, Ontario Veterinary College, University of Guelph, 50 Stone Road East, Guelph, ON NIG 2W1, Canada

7 Ottawa Hospital, Civic Campus, 1053 Carling Avenue Administrative Services Building, Box 684, Ottawa, ON K1Y 4E9, Canada

8 Department of Biology, Carleton University, 1125 Colonel By Drive, Ottawa, ON K1S 5B6, Canada

9 Corinne School of Epidemiology and Public Health, University of Ottawa, 600 Peter Morand Crescent, Room 205, Ottawa, ON K1G 3Z7, Canada 